\title{
Preparação e caracterização de membranas cerâmicas de cordierita
}

\section{(Preparation and characterization of cordierite ceramic membranes)}

\author{
F. A. Silva, H. L. Lira \\ Departamento de Engenharia de Materiais, Universidade Federal de Campina Grande \\ Av. Aprígio Veloso, 882, Campina Grande, PB 58109-970 \\ fernando@labdes.ufcg.edu.br
}

\begin{abstract}
Resumo
As membranas cerâmicas encontram larga aplicação, principalmente em processos cujas temperaturas de trabalho são superiores a 250 ${ }^{\circ} \mathrm{C}$, como também na separação de soluções em que o $\mathrm{pH}$ é extremamente ácido, ou mesmo quando há solventes orgânicos no sistema. Em contrapartida, as membranas cerâmicas apresentam a desvantagem de apresentar um alto custo de fabricação, principalmente em relação às matérias-primas que são geralmente sintéticas (zirconia, alumina, titânia e sílica). Atualmente, o principal foco de preocupação no desenvolvimento destas membranas é otimizar os custos de produção, encontrando matérias-primas naturais a preços mais competitivos, além de processos de produção mais eficientes, como a extrusão. A produção de membranas por extrusão permite sua utilização em processos de fluxo tangencial, possibilitando a sua aplicação em microfiltração. Este trabalho consistiu na confecção de membranas tubulares de cordierita obtidas a partir de matérias-primas naturais, tais como argilas e talco, e pelo processo de extrusão. Foram utilizadas quatro temperaturas de sinterização $\left(1150,1200,1250\right.$ e $\left.1280^{\circ} \mathrm{C}\right)$, objetivando mostrar a influência destas temperaturas nas características das membranas. Foi feito o ensaio de difração de raios X na massa após a sinterização, e o resultado mostrou a formação da cordierita nas quatro sinterizações efetuadas. Com relação às dimensões e a distribuição dos poros das membranas, os resultados de microscopia eletrônica de varredura e de porosimetria através de intrusão de mercúrio mostraram poros com tamanhos de $1,4,2,2,3,3$ e $4,1 \mu \mathrm{m}$ e porosidade de $28,7,29,1,27,7$ e $24,3 \%$, para as temperaturas de sinterização $1150,1200,1250$ e $1280{ }^{\circ} \mathrm{C}$, respectivamente, caracterizando-as como membranas para microfiltração. Os ensaios de permeabilidade através de aplicação de fluxo tangencial com água destilada mostraram que as membranas sinterizadas a $1280{ }^{\circ} \mathrm{C}$ obtiveram maior permeabilidade, seguindo-se das de $1250^{\circ} \mathrm{C}, 1200^{\circ} \mathrm{C}$ e as de $1150^{\circ} \mathrm{C}$. Os valores médios dos fluxos encontrados nas membranas sinterizadas nas temperaturas de 1150 , 1200,1250 e $1280^{\circ} \mathrm{C}$ foram de aproximadamente $68,143,378$ e $587 \mathrm{~kg} / \mathrm{h} . \mathrm{m}^{2}$, respectivamente.
\end{abstract}

Palavras-chave: cordierita, membrana cerâmica, sinterização.

Abstract

Membrane separation processes find large applications. Ceramic membranes are applied in several processes, mainly in application above $250^{\circ} \mathrm{C}$, as well as in separation of solutions with $\mathrm{pH}$ extremely acid and even in systems with organic solvents. On the other hand, ceramic membranes show high cost of fabrication, mainly in relation to the raw synthetic materials (zirconia, alumina, titania and silica). Therefore, the main concern in the development of these membranes is to optimize the cost using natural non-expensive raw materials and more efficient ceramic processing, such as extrusion. The fabrication of ceramic membranes by extrusion gives the possibility to use cross flow system, which is very useful in microfiltration and ultrafiltration separation processes. The aim of this work is to prepare tubular cordierite membranes from raw materials such as clays and talc and by extrusion processing. Four sintering temperatures $\left(1150,1200,1250\right.$ and $1280{ }^{\circ} \mathrm{C}$ ) were used to show the effect on the morphological characteristics of the membranes. The membranes were characterized by X-ray diffraction, scanning electron microscopy and mercury intrusion porosimetry. The results showed the formation of cordierite phase at all sintering temperatures. The membranes presented pore size of 1.4, 2.2, 3.3 and $4.1 \mu \mathrm{m}$ and porosity content of 28.7, 29.1, 27.7 and 24.3\% for sintering temperaturesf 1150, 1200, 1250 and $1280{ }^{\circ} \mathrm{C}$, respectively. These values show that these membranes are suitable to be applied in microfiltration separation processes. The results of water flux, at steady state, show that the membrane sintered at $1280{ }^{\circ} \mathrm{C}$ presented the highest value, $587.3 \mathrm{~kg} / \mathrm{m}^{2} . h$, followed by $377.7 \mathrm{~kg} / \mathrm{m}^{2} . \mathrm{h}\left(1250^{\circ} \mathrm{C}\right), 143.4 \mathrm{~kg} / \mathrm{m}^{2} . \mathrm{h}\left(1200^{\circ} \mathrm{C}\right)$ and $67.8 \mathrm{~kg} / \mathrm{m}^{2} . \mathrm{h}\left(1150^{\circ} \mathrm{C}\right)$.

Keywords: cordierite, ceramic membrane, sintering

\section{INTRODUÇÃO}

As membranas são amplamente empregadas em processos de separação nas áreas de tratamento de rejeitos industriais, processamento de alimentos, dessalinização de águas, processos biomédicos, têxteis e químicos [1-3].

Diversos estudos têm demonstrado que a utilização das membranas cerâmicas apresenta vantagens em relação às poliméricas, principalmente no que se refere à inércia química, estabilidade biológica e resistência a altas temperaturas e pressões. Um outro ponto importante é a vantagem que as membranas cerâmicas apresentam em relação aos métodos tradicionais de separação (destilação, centrifugação, etc.), como, baixo consumo de energia, vida 
útil longa, ocupação de pouco espaço físico e facilidade de limpeza $[2,4]$.

O grande avanço tecnológico alcançado nos processos de produção de cerâmica possibilita a obtenção de membranas com formatos complexos para propiciar grandes áreas superficiais e, assim, adequá-las ao uso em pequenos espaços físicos, aumentando a permeabilidade do sistema. Isto tudo, com um controle rigoroso no tamanho e na distribuição dos poros, para permitir uma alta seletividade e tornando viável a utilização de tais membranas em microfiltração, ultrafiltração e, mais recentemente, em nanofiltração [5].

O número de aplicações das membranas cerâmicas é imenso e está sempre aumentando. Estima-se que dentre os processos de separação por membranas, as membranas de cerâmica têm crescido cerca de $15 \%$ ao ano, apesar dos conhecimentos detalhados sobre aplicações comerciais ainda serem restritos [6].

Vários materiais cerâmicos têm sido usados na fabricação de membranas, dentre os quais se destacam a alumina, o óxido de silício, a zircônia e a titânia [7]. Muitos outros materiais, como mulita e cordierita também têm sido mencionados na preparação de membranas cerâmicas [8].

A cordierita sintética tem um grande leque de aplicações, tais como: na indústria de microeletrônica, nas fundições, em equipamentos térmicos e, mais recentemente, na produção de membranas. Esta versatilidade de aplicações deve-se a várias características intrínsecas à cordierita sintética, quais sejam: baixa constante dielétrica, alta resistividade, baixo coeficiente de expansão térmica, alta resistência ao choque térmico, elevada estabilidade térmica e química e boas propriedades mecânicas. Dependendo da composição da massa e da tecnologia aplicada à preparação, a cordierita sintética pode ter diferentes densidades, desde 1,9 até 2,6 $\mathrm{g} / \mathrm{cm}^{3}[9]$.

Poucos trabalhos têm sido publicados sobre membranas de cordierita, sendo estes estudos restritos ao uso destas como suporte para membranas cerâmicas assimétricas. Geralmente, para formação da camada ativa são utilizados os óxidos de alumínio, de zircônio, de silício ou de titânio [10-16]. Todos estes materiais têm boa afinidade com a cordierita. Na maioria das vezes, o depósito destes materiais no suporte de cordierita é feito por imersão.

Este trabalho tem como objetivo produzir membranas cerâmicas tubulares de cordierita a partir de matériasprimas naturais e sinterizadas em diferentes temperaturas, com o intuito de verificar sua aplicabilidade em microfiltração.

\section{MATERIAIS E MÉTODOS}

\section{Materiais}

Para produção das membranas cerâmicas foram utilizadas as seguintes matérias-primas: argila ball clay (Alhandra, PB) (45\%), bentonita (Boa Vista, PB) (3\%), talco (Ponta Grossa, PR) $(17 \%)$ e chamota (obtida após calcinação da argila ball clay) $(35 \%)$.

\section{Método}

Inicialmente as materiais-primas foram submetidas à moagem a úmido. A barbotina formada foi descarregada em tanque de homogeneização. Em seguida foi submetida à secagem e triturada até a forma de pó. A massa foi levada até um misturador planetário onde se adicionou água e aditivos líquidos até a obtenção de uma massa homogênea e com plasticidade adequada ao processo de extrusão. A extrusão foi feita numa extrusora a vácuo Verdés modelo 051. O molde utilizado foi confeccionado em aço VC 131, temperado, o qual permitiu que as peças extrudadas adquirissem a forma tubular com as seguintes dimensões: diâmetro externo 10,9 mm e diâmetro interno $7,7 \mathrm{~mm}$.

As peças extrudadas foram submetidas a duas etapas de secagem. Na primeira, as peças foram submetidas a secagem natural lenta, durante cinco dias. Na segunda, foram levadas a uma estufa com temperatura controlada em $95^{\circ} \mathrm{C}$ por 36 h. Após a secagem, as peças cerâmicas tubulares foram cortadas com comprimento aproximado de $100 \mathrm{~mm}$.

As peças foram sinterizadas obedecendo a quatro curvas de queima diferentes. As sinterizações foram realizadas em forno elétrico Maitec. A sinterização das membranas foi feita baseando-se na curva da analise termogravimétrica da massa cerâmica. As taxas de aquecimento foram as seguintes: $2{ }^{\circ} \mathrm{C} /$ min a partir da temperatura ambiente a $200{ }^{\circ} \mathrm{C}, 1{ }^{\circ} \mathrm{C} / \mathrm{min}$ de $200{ }^{\circ} \mathrm{C}$ a $400{ }^{\circ} \mathrm{C}$ e $3{ }^{\circ} \mathrm{C} / \mathrm{min}$ de $400{ }^{\circ} \mathrm{C}$ até atingir as seguintes temperaturas: (a) $1^{\text {a }}$ curva $1150{ }^{\circ} \mathrm{C}$, (b) $2^{\text {a }}$ curva $1200^{\circ} \mathrm{C}$, (c) $3^{\text {a }}$ curva $1250{ }^{\circ} \mathrm{C}$, (d) $4^{\mathrm{a}}$ curva $1280^{\circ} \mathrm{C}$. O tempo no patamar de queima foi $1 \mathrm{~h}$. Após o patamar de sinterização, o forno foi desligado, resfriando-se naturalmente por um período de $12 \mathrm{~h}$, atingindo assim, $100{ }^{\circ} \mathrm{C}$, quando então, as membranas foram retiradas do forno e deixadas até a temperatura ambiente.

As membranas cerâmicas foram caracterizadas por ensaios de microscopia eletrônica de varredura, porosimetria pelo método de intrusão de mercúrio e permeabilidade por meio de fluxo tangencial.

A microestrutura das membranas cerâmicas, bem como, a distribuição e tamanho de poros foi avaliada por meio das micrografias obtidas pelo microscópio eletrônico de varredura LEO 1430, resolução de 3,5 nm a $30 \mathrm{kV}$ (tungstênio), faixa de magnificação: de 15 a 300.000 vezes. Este ensaio foi realizado no Laboratório de Solidificação Rápida do Depto. de Engenharia Mecânica da UFPB. O ensaio de porosimetria de mercúrio das membranas sinterizadas foi realizado no Laboratório de Processos Cerâmicos do Depto. de Engenharia Metalúrgica e de Materiais da Escola Politécnica da USP em porosímetro Auto Pore 9.400 Micromeritics.

Para medida de fluxo tangencial foi usado um sistema montado no Laboratório de Referência em Dessalinização na UFCG. Foram testadas 12 amostras de membranas cerâmicas, sendo três de cada temperatura de sinterização.

A Fig. 1 mostra uma representação esquemática do sistema de fluxo tangencial usado para medida da permeação da água destilada através da membrana cerâmica, consistindo de um tanque de alimentação, uma bomba para circulação do liquido e o reator com a membrana tubular em seu interior. 


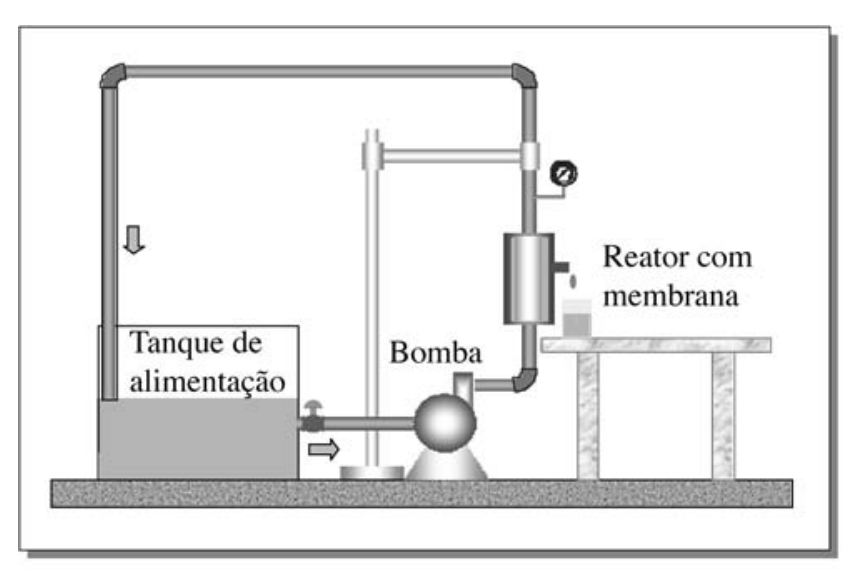

Figura 1: Representação esquemática do sistema para medida de fluxo tangencial de membrana tubular.

[Figure 1: Schematic representation of the cross flow system to tubular membrane.]

\section{RESULTADOS E DISCUSSÃO}

\section{Análise granulométrica}

A Fig. 2 apresenta a distribuição granulométrica das partículas da massa cerâmica após moagem e mistura. Considerando-se que a fração argila tem partículas de tamanho menor que $2 \mu \mathrm{m}$, verifica-se que a massa apresenta um baixo percentual da fração argila. Em relação à fração silte, com partículas entre 2 e $20 \mu \mathrm{m}$, verifica-se o maior percentual. A fração areia, cujas partículas têm tamanho superior a 20 $\mu \mathrm{m}$, verifica-se também um pequeno percentual. O diâmetro médio das partículas é $\sim 7,5 \mu \mathrm{m}$, portanto é de se esperar que as membranas obtidas com esta massa apresentem tamanho médio de poros da ordem de 2-5 $\mu \mathrm{m}$ [7].

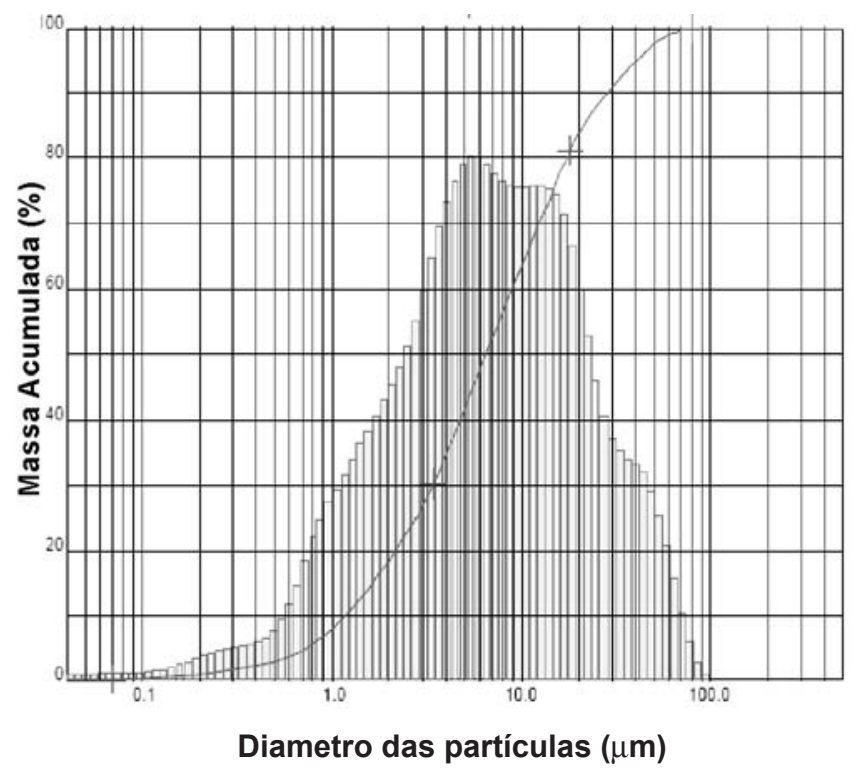

Figura 2: Distribuição granulométrica da massa cerâmica à verde. [Figure 2: Size distribution of green ceramic paste.]

\section{Análise termogravimétrica}

A Fig. 3 mostra a curva da análise termogravimétrica da massa cerâmica. Observa-se uma perda de massa de $2 \%$ até $200{ }^{\circ} \mathrm{C}$, proveniente da água. De 200 a $500{ }^{\circ} \mathrm{C}$ observa-se uma acentuada perda de massa, em torno de $11 \%$, em conseqüência da perda de matéria orgânica e de hidroxilas da fração argila. A partir dos $500{ }^{\circ} \mathrm{C}$ até o final do processo ocorre uma perda de massa de $5 \%$, provocado pela decomposição e perda de carbonatos e hidróxidos. A perda total de massa foi de aproximadamente $16 \%$.

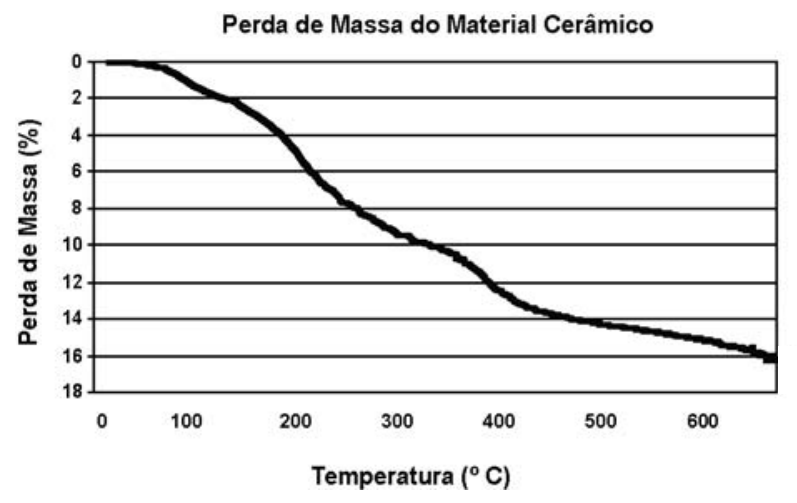

Figura 3: Análise termogravimétrica da massa cerâmica a verde. [Figure 3: TG curve of the green ceramic paste.]

\section{Análise química}

A Tabela I apresenta a composição química das matériasprimas e da massa cerâmica a verde. Verifica-se que as matérias-primas possuem altos teores de $\mathrm{SiO}_{2}$. A argila ball clay e a bentonita possuem elevados teores $\mathrm{de} \mathrm{Al}_{2} \mathrm{O}_{3}$ e Fe${ }_{2} \mathrm{O}_{3}$, sendo este último responsável pela coloração vermelha após a sinterização. O talco tem um teor de $\mathrm{MgO}$ superior a $30 \%$, contribuindo para a composição típica de massas plásticas para obtenção de cordierita.

Tabela I - Composição química das matérias-primas e da massa cerâmica verde.

[Table I-Chemical composition of the raw materials and green ceramic past.]

\begin{tabular}{lcccc}
\hline $\begin{array}{l}\text { Óxidos } \\
(\% \text { em peso })\end{array}$ & $\begin{array}{c}\text { Argila } \\
\text { Ball } \\
\text { Clay }\end{array}$ & Bentonita & $\begin{array}{c}\text { Talco } \\
\text { Massa } \\
\text { cerâmica } \\
\text { a verde }\end{array}$ \\
\hline Perda ao fogo $(\mathrm{PF})$ & 12,60 & 20,47 & 3,64 & 15,69 \\
Resíduo insolúvel $(\mathrm{RI})$ & 1,15 & 2,74 & 2,16 & 1,16 \\
Óxido de Silício $\left(\mathrm{SiO}_{2}\right)$ & 49,34 & 46,10 & 57,36 & 40,07 \\
Óxido de alumínio $\left(\mathrm{Al}_{2} \mathrm{O}_{3}\right)$ & 20,50 & 21,09 & 4,55 & 29,04 \\
Óxido de Ferro $\left(\mathrm{Fe}_{2} \mathrm{O}_{3}\right)$ & 6,87 & 7,66 & Traços & 2,71 \\
Óxido de cálcio $(\mathrm{CaO})$ & 3,50 & Traços & Traços & Traços \\
Óxido de magnésio $(\mathrm{MgO})$ & Traços & Traços & 31,26 & 10,33 \\
Óxido de sódio $\left(\mathrm{Na}_{2} \mathrm{O}\right)$ & 2,40 & 1,68 & 0,10 & 0,07 \\
Óxido de potássio $\left(\mathrm{K}_{2} \mathrm{O}\right)$ & 3,00 & 0,22 & 0,13 & 0,09 \\
\hline
\end{tabular}




\section{Difração de raios $X$}

A Fig. 4 mostra o resultado da difração de raios $X$ da massa cerâmica a verde. $\mathrm{O}$ difratograma registra a presença de montmorilonita, caracterizada pela distância interplanar

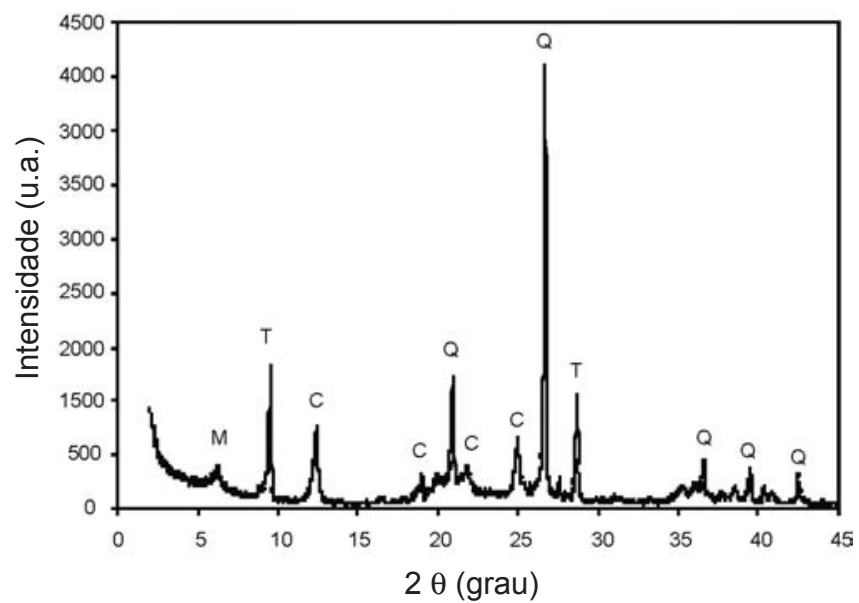

Legenda: Montmorilonita - M; Talco - T; Caulita - C; Quartzo - Q

Figura 4: Difratogramas de raios $\mathrm{X}$ da massa cerâmica à verde. [Figure 4: X-ray diffraction patterns of the green ceramic paste.]
14,39 A, de talco, caracterizado pela distância de 9,38 A e 3,12 A, de caulinita, caracterizada por 7,19, 4,46, 4,09 e 3,58 A e de quartzo, caracterizado por 4,26, 3,34, 2,28, e 2,13 A.

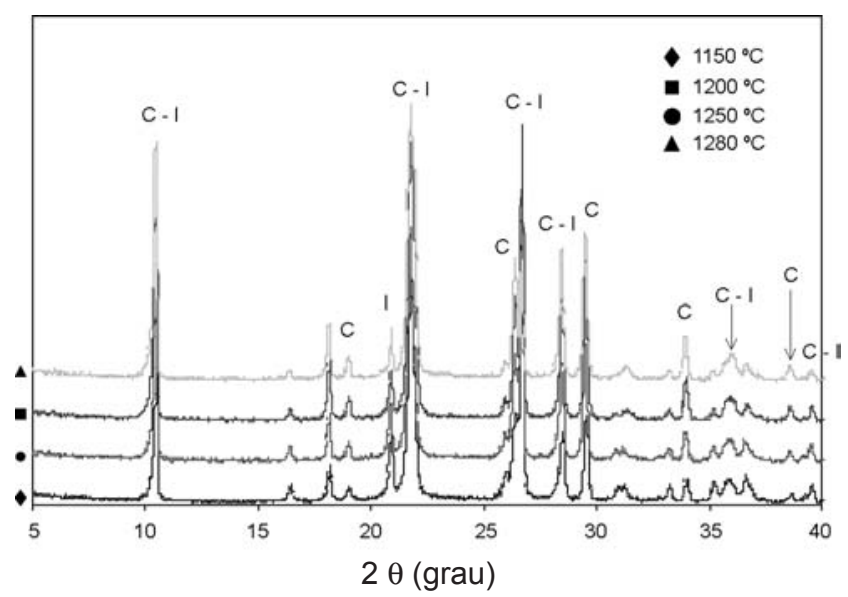

Legenda: Vordierita - C; Indalita - I

Figura 5: Difratogramas de raios $\mathrm{X}$ das massas cerâmicas sinterizadas a $1150,1200,1250$ e $1280^{\circ} \mathrm{C}$.

[Figure 5: X-ray diffraction of the ceramic bodies sintered at 1150 , 1200, 1250 and $1280{ }^{\circ} \mathrm{C}$.] (a)

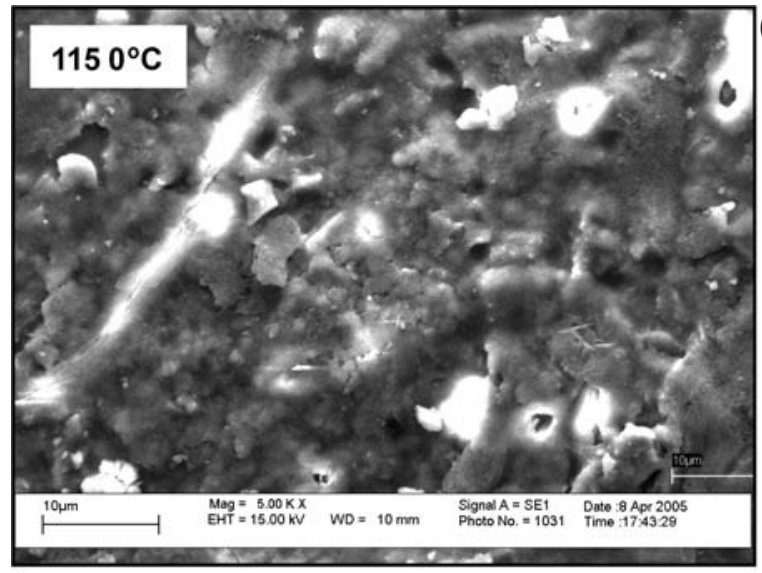

(c)

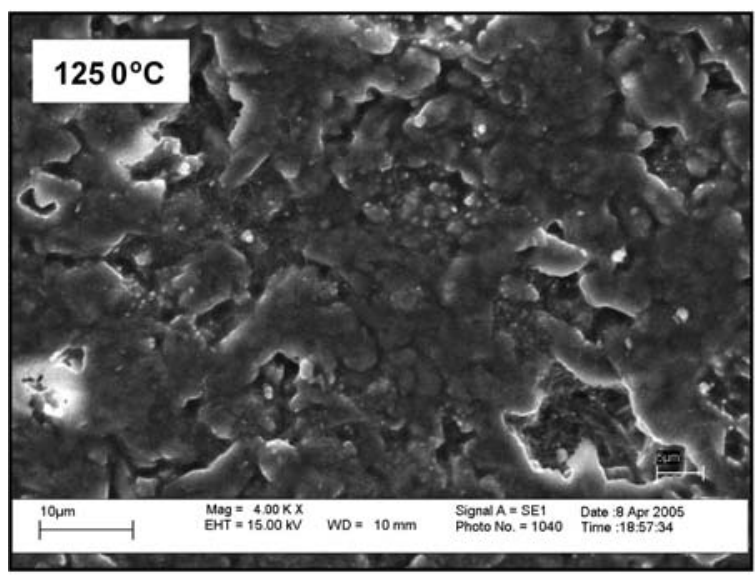

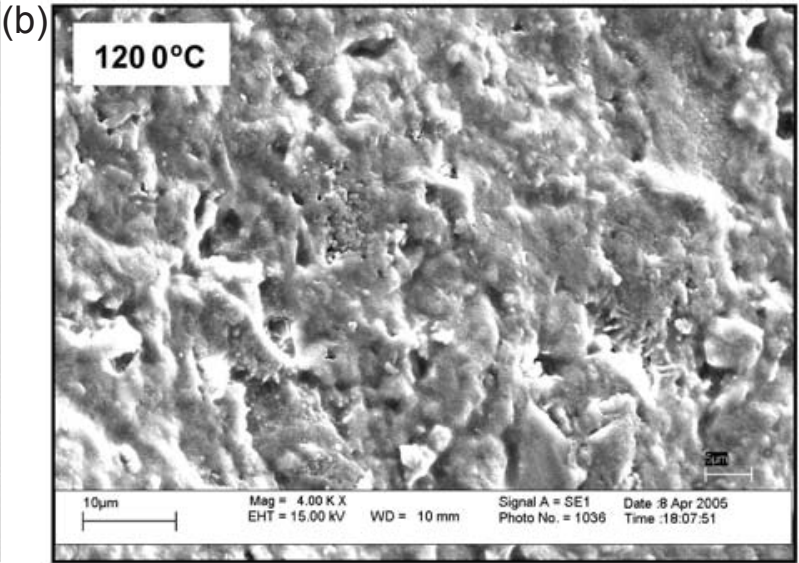

(d)

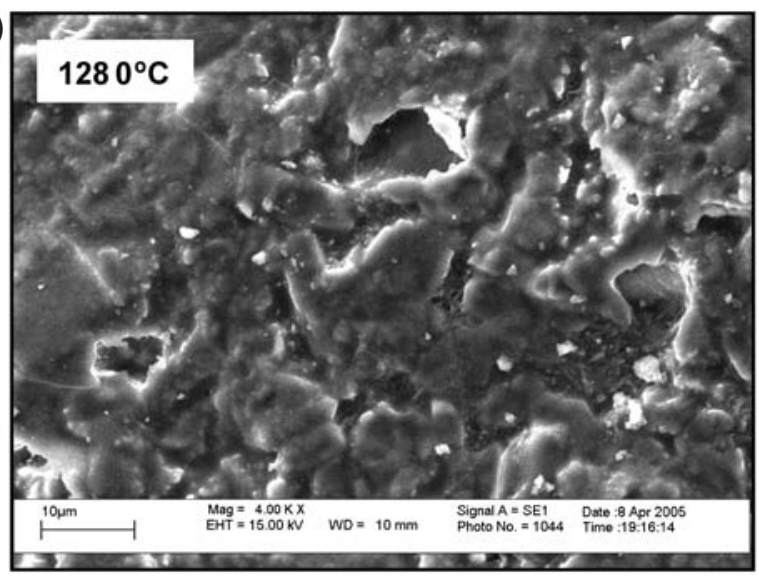

Figura 6: Micrografias obtifas por MEV das membranas de cordierita sinterizadas a $1150,1200,1250$ e $1280^{\circ} \mathrm{C}$.

[Figure 6: SEM micrographs of the cordierite membranes sintered at 1150, 1200, 1250 and $1280{ }^{\circ} \mathrm{C}$.] 
A Fig. 5 mostra o resultado da difração de raios $\mathrm{X}$ da massa cerâmica sinterizada. Observa-se a presença de picos relativa à cordierita $\mathrm{e}$ indialita, nas quatro diferentes temperaturas de sinterização efetuadas e com aumento da intensidade dos picos com o aumento da temperatura de sinterização de 1150 a $1280{ }^{\circ} \mathrm{C}$. Isto comprova que a composição da massa estudada favoreceu a formação de cordierita após sinterização.

\section{Microscopia eletrônica de varredura}

A Fig. 6 mostra micrografias das membranas de cordierita sinterizadas a $1150,1200,1250$ e $1280{ }^{\circ} \mathrm{C}$. Verifica-se a ausência de trincas ou defeitos superficiais. Foram observados poros, todos menores que $10 \mu \mathrm{m}$, o que se pode caracterizar como membranas para microfiltração. As micrografias não permitem estimar com precisão o tamanho dos poros nas diferentes membranas, no entanto verifica-se uma diferença no aspecto superficial das micrografias, com as membranas sinterizadas em temperaturas maiores, $1280{ }^{\circ} \mathrm{C}$, apresentando poros maiores e em menor quantidade, porém essas observações não são conclusivas.

\section{Porosimetria pelo método de intrusão de mercúrio}

As Figs. 7, 8, 9 e 10 apresentam os gráficos do diâmetro médio de poros em função do volume de intrusão acumulada de mercúrio para as quatro sinterizações efetuadas. As amostras apresentam a grande maioria de poros variando de 1,0 a $10 \mu \mathrm{m}$, confirmando assim o que foi observado no ensaio de microscopia eletrônica de varredura.

Os valores do diâmetro médio dos poros e da porosidade das membranas de cordierita e sua relação com a temperatura de sinterização são mostrados na Tabela II. Verificou-se que a elevação da temperatura de sinterização provocou diminuição da porosidade. A elevação da temperatura de sinterização provocou, além de um crescimento de grãos, a formação de fase liquida, conferindo uma maior densificação.

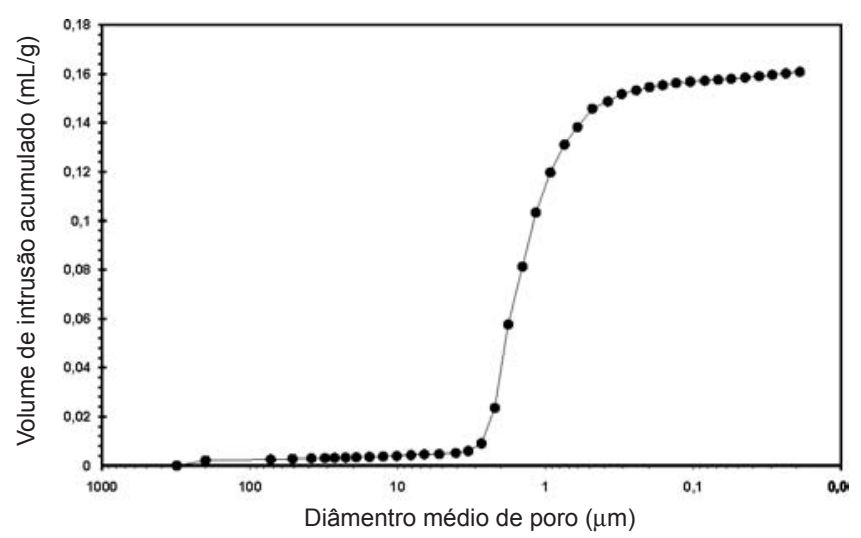

Figura 7: Diâmetro médio de poros em função do volume de intrusão de mercúrio acumulado na membrana de cordierita sinterizada a $1150{ }^{\circ} \mathrm{C}$.

[Figure 7: Pore size distribution as a function of mercury intrusion volume for the cordierite membrane sintered at $1150^{\circ} \mathrm{C}$.]

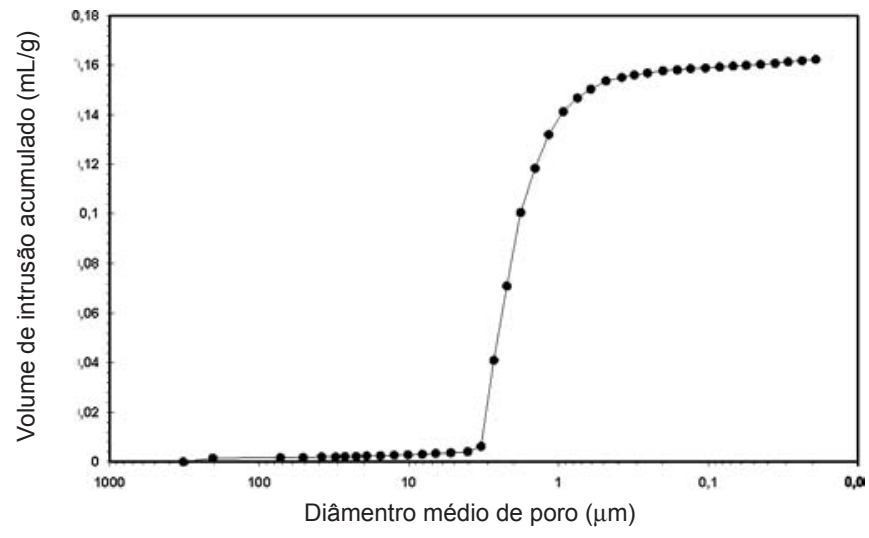

Figura 8: Diâmetro médio de poros em função do volume de intrusão de mercúrio acumulado na membrana de cordierita sinterizada a $1200^{\circ} \mathrm{C}$.

[Figure 8: Pore size distribution as a function of mercury intrusion volume for the cordierite membrane sintered at $1200^{\circ} \mathrm{C}$.]

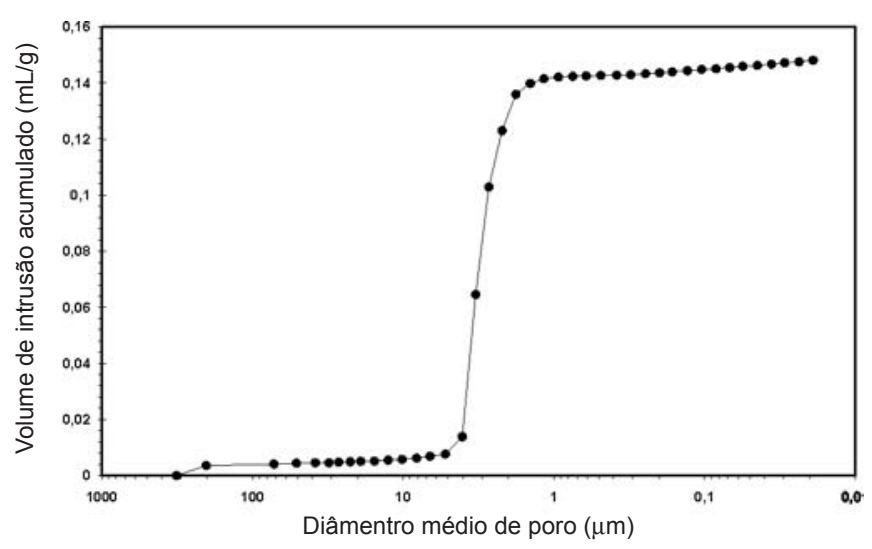

Figura 9: Gráfico do diâmetro médio de poros em função do volume de intrusão de mercúrio acumulado na membrana de cordierita sinterizada a $1250{ }^{\circ} \mathrm{C}$.

[Figure 9: Pore size distribution as a function of mercury intrusion volume for the cordierite membrane sintered at $1250^{\circ} \mathrm{C}$.]

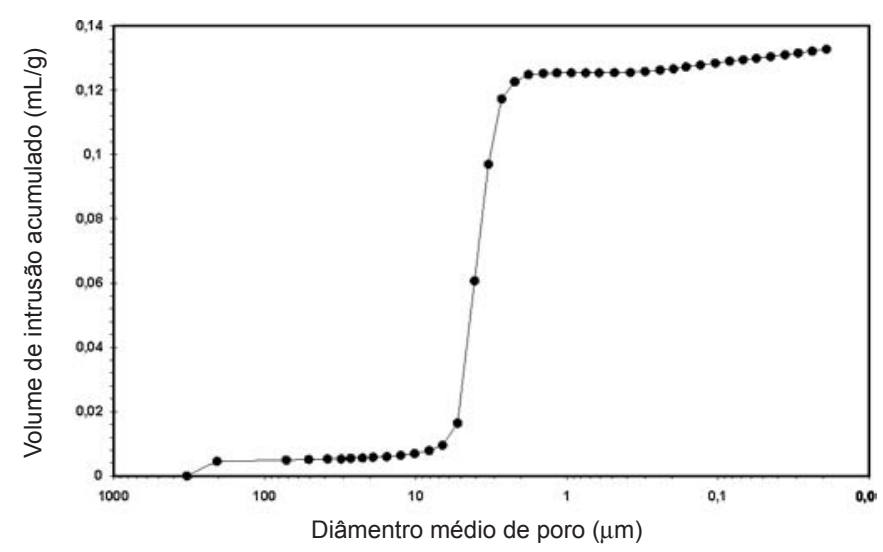

Figura 10: Gráfico do diâmetro médio de poros em função do volume de intrusão de mercúrio acumulado na membrana de cordierita sinterizada a $1280{ }^{\circ} \mathrm{C}$.

[Figure 10: Pore size distribution as a function of mercury intrusion volume for the cordierite membrane sintered at $1280{ }^{\circ} \mathrm{C}$.] 
Tabela II - Diâmetro médio dos poros e da porosidade das membranas de cordierita sinterizadas a $1150,1200,1250 \mathrm{e}$ $1280{ }^{\circ} \mathrm{C}$.

[Table II - Pore size and porosity of the cordierite membranes sintered at temperatures of $1150,1200,1250$ and $1280{ }^{\circ} \mathrm{C}$.]

\begin{tabular}{ccc}
\hline $\begin{array}{c}\text { Temperatura de } \\
\text { Sinterização }\left({ }^{\circ} \mathrm{C}\right)\end{array}$ & $\begin{array}{c}\text { Diâmetro Médio } \\
\text { dos Poros }(\mu \mathrm{m})\end{array}$ & Porosidade (\%) \\
\hline 1150 & 1,430 & 28,72 \\
1200 & 2,213 & 29,11 \\
1250 & 3,299 & 27,68 \\
1280 & 4,070 & 24,34 \\
\hline
\end{tabular}

Por outro lado, verificou-se que a elevação da temperatura também provocou o aumento no diâmetro médio dos poros das membranas. Isto se deve provavelmente ao escoamento da fase líquida formada, preenchendo os poros menores e consequentemente aumentando os poros maiores. De maneira geral, verifica-se que com o aumento da temperatura de sinterização ocorreu uma diminuição da porosidade e um aumento no tamanho dos poros remanescente.

\section{Medidas de fluxo das membranas}

Os resultados dos fluxos de água destilada que permeiam através das membranas de cordierita sinterizadas a 1150 , 1200,1250 e $1280{ }^{\circ} \mathrm{C}$ estão mostrados na Fig. 11. Foram ensaiadas 3 amostras para cada temperatura de sinterização, sendo cada curva a media das 3 análises. A membrana que obteve maior fluxo foi a sinterizada a $1280^{\circ} \mathrm{C}$, seguindo-se da de $1250{ }^{\circ} \mathrm{C}, 1200{ }^{\circ} \mathrm{C}$, e a de $1150{ }^{\circ} \mathrm{C}$. Observou-se que os fluxos permeados através das membranas sinterizadas, na mesma temperatura de queima, apresentaram resultados com uma pequena variação entre elas, mostrando assim, certa homogeneidade e membranas livre de defeitos (formação de trincas).

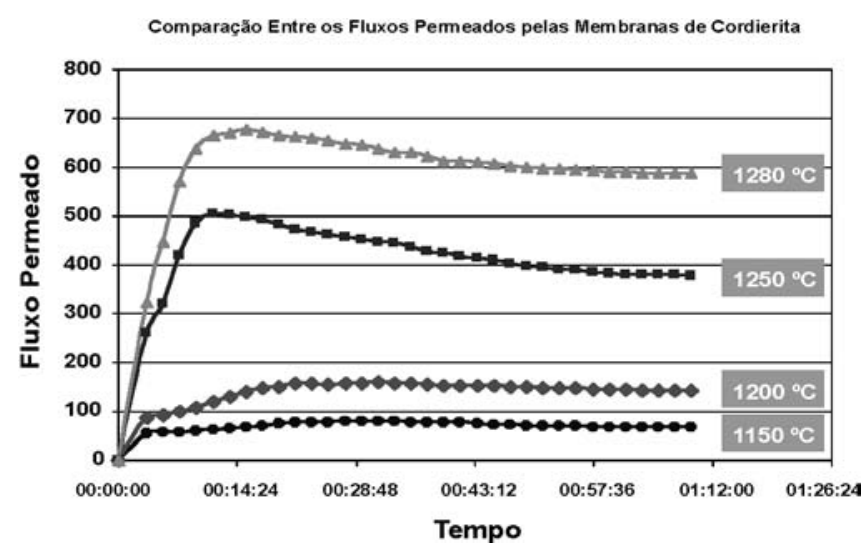

Figura 11: Gráfico comparativo dos fluxos de água destilada permeados através das membranas de cordierita sinterizadas a $1150,1200,1250$ e $1280{ }^{\circ} \mathrm{C}$.

[Figure 11: Curves of distilled water flow through the cordierite membranes sintered at temperatures of 1150, 1200, 1250 and $1280^{\circ} \mathrm{C}$.]
O maior fluxo permeado foi verificado nas amostras sinterizada a $1280{ }^{\circ} \mathrm{C}$, observando-se um valor de 587,3 $\mathrm{kg} / \mathrm{h} \cdot \mathrm{m}^{2}$, após a estabilização (neste ponto diz-se que o sistema atingiu o "estado estável", onde o fluxo de água destilada é tomado como referência para membrana) após aproximadamente $1 \mathrm{~h}$ de funcionamento do sistema. A Tabela III mostra os valores médios dos fluxos permeados nas membranas sinterizadas em diferentes temperaturas e no

Tabela III - Valores médios dos fluxos permeados, no estado estacionário, através das membranas de cordierita sinterizadas a $1150,1200,1250$ e $1280^{\circ} \mathrm{C}$.

[Table III - Water flow through the cordierite membranes sintered at $1150,1200,1250$ and $1280{ }^{\circ} \mathrm{C}$.]

\begin{tabular}{cc}
\hline $\begin{array}{c}\text { Temperatura de Sinterização } \\
\text { das Membranas }\left({ }^{\circ} \mathrm{C}\right)\end{array}$ & $\begin{array}{c}\text { Fluxo Permeado } \\
\left(\mathrm{kg} / \mathrm{h} . \mathrm{m}^{2}\right)\end{array}$ \\
\hline 1150 & 67,8 \\
1200 & 143,4 \\
1250 & 377,7 \\
1280 & 587,3 \\
\hline
\end{tabular}

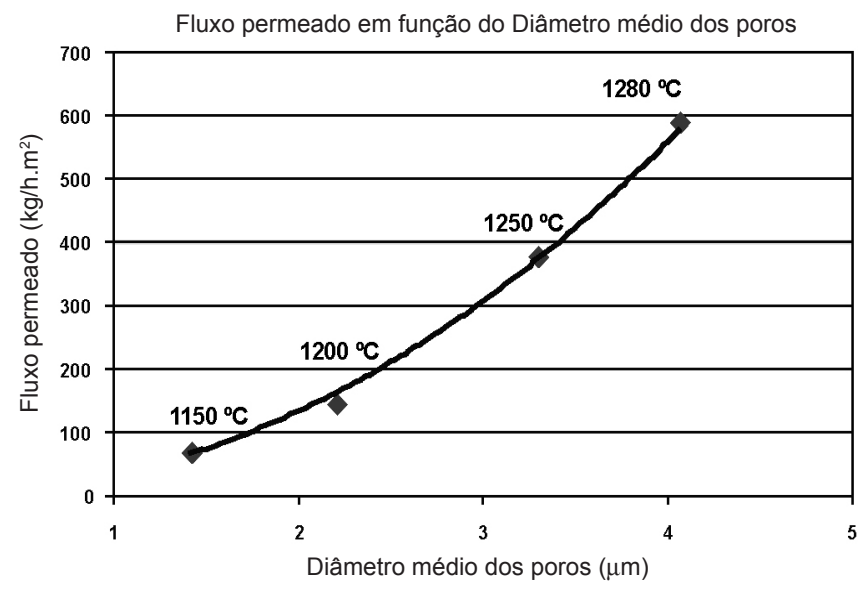

Figura 12: Fluxo permeado em função do diâmetro médio dos poros das membranas de cordierita sinterizadas a 1150, 1200, 1250 e $1280{ }^{\circ} \mathrm{C}$.

[Figure 12: Water flow as a function of pore size of the cordierite membranes sintered at temperatures of 1150, 1200, 1250 and $\left.1280{ }^{\circ} \mathrm{C}.\right]$

"estado estável". Verifica-se que o aumento da temperatura de sinterização das membranas provocou um aumento no fluxo permeado. Isto mostra que o fluxo permeado através da membrana é mais sensível à variação dos diâmetros médios dos poros do que da sua porosidade, como pode ser visto na Fig. 12.

Comparativamente, verifica-se que a membrana de $1150{ }^{\circ} \mathrm{C}$ apresenta apenas $11,5 \%$ do fluxo da membrana de $1280{ }^{\circ} \mathrm{C}$, enquanto que a membrana de $1200{ }^{\circ} \mathrm{C}$ apresenta $24,4 \%$ e a membrana de $1250{ }^{\circ} \mathrm{C}$ apresenta $64,3 \%$ do fluxo da membrana de $1280{ }^{\circ} \mathrm{C}$. 


\section{CONCLUSÕES}

Membranas cerâmicas tubulares de cordierita foram preparadas com sucesso, livre de defeitos (trincas) e com tamanho de poros na faixa de microfiltração (1-4 $\mu \mathrm{m})$.

A elevação da temperatura de sinterização provocou aumento no diâmetro médio dos poros e uma diminuição na porosidade das membranas de cordierita.

O fluxo com água destilada foi maior para as membranas de cordierita sinterizadas em maiores temperaturas, nas quais o aumento no diâmetro médio dos poros teve maior influencia do que a redução na porosidade.

\section{AGRADECIMENTOS}

Ao CNPq pela concessão da bolsa DTI, Proc. 381150/054 e ao Laboratório de Dessalinisação (LABDES) do Centro de Ciências e Tecnologia da UFCG, pelo uso de suas instalações e apoio à pesquisa.

\section{REFERÊNCIAS}

[1] R. Soria, Catalysis Today 25 (1995) 285-290.

[2] R. R. Bhave, Inorganic Membranes. Synthesis Characteristics and Applications, $1^{\text {st }}$ Ed., Van Nostrand Renhold, New York (1991) 19.

[3] F. Quemeneur, P. Jaouen, Proc. $2^{\text {nd }}$ Int. Conf. Inorg. Membranes, Montpellier, France (1991) 585.
[4] K. W. Boddeker, J. Membrane Sci. 100 (1995) 65.

[5] M. Mulder, Basic Principles of Membrane Technology.

$1^{\text {st }}$ Ed., Kluver Academic Publishers, Netherlands (1991) 75.

[6] R. J. R. Uhlhorn, K. Keizer, A. J. Burggraaf, J. Membrane Sci. 66 (1992) 271.

[7] A. J. Burggraaf, L. Cot, Fundamentals of Inorganic Membranes Science and Technology, $1^{\text {st }}$ Ed., Elsevier, Amsterdam (1996) 21.

[8] L. Zhou, T. Wang, Q. T. Nguyen, J. Li, Y. Long, Z. Ping, Separation Purification Technology 44, 3 (2005) 266.

[9] Z. Acimovic, L. Pavlovic, L. Trumbulovic, L. Andric, M. Stamatovic, Mater. Lett. 57 (2003) 2651.

[10] J. M. Benito, A. Conesa, M. A. Rodriguez, Bol. Soc. Esp. Ceram. Vid. 43, 5 (2004) 829.

[11] R. R. Bhave, Inorganic Membranes: Synthesis, Characteristics, and Applications $1^{\text {st }}$ Ed., Van Nostrand Reinhold, New York (1991) 10.

[12] L. Cot, J. Chim Phys. 88 (1991) 2083.

[13] H. P. Hsieh, Inorganic Membranes for Separation and Reaction. ${ }^{\text {st }}$ Ed., Elsevier, Amsterdam (1996) 23.

[14] S. Kitao, M. Ishizaki, M. Asaeda, Key Eng. Mater. 61 (1991) 175.

[15] A. Larbot, A. Julbe, J. Randon, C. Guizard, L. Cot, First Int. Conf. Inorg. Membrane, Montpellier, France, (1989) 381.

[16] H. L. Lira, R. Paterson, J. Membrane Sci. 206 (2002) 375. (Rec. 16/02/2006, Rev. 25/05/2006, Ac. 04/08/2006) 